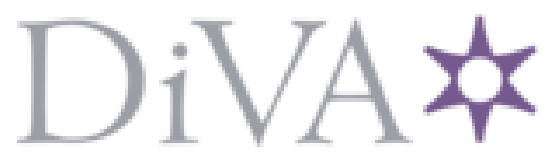

http://www.diva-portal.org

This is the published version of a paper presented at 24th Australian Computer-Human Interaction Conference, OzCHI 2012, 26 November 2012 through 30 November 2012, Melbourne, VIC.

Citation for the original published paper:

Tobiasson, H., Hedman, A., Sundblad, Y. (2012)

Design space and opportunities for physical movement participation in everyday life.

In: Proceedings of the 24th Australian Computer-Human Interaction Conference, OzCHI 2012 (pp. 607-615). ACM

http://dx.doi.org/10.1145/2414536.2414628

N.B. When citing this work, cite the original published paper.

Permanent link to this version:

http://urn.kb.se/resolve?urn=urn:nbn:se:kth:diva-1 16854 


\section{Design Space and Opportunities for Physical Movement Participation in Everyday Life}

\author{
Helena Tobiasson \\ Kungliga Tekniska Högskolan, \\ $\mathrm{KTH}$ \\ School of Computer Science \\ and Communication, CSC \\ Valhallav. 79 \\ 10044 Stockholm \\ Sweden \\ tobi@csc.kth.se
}

\author{
Anders Hedman \\ Kungliga Tekniska Högskolan, \\ $\mathrm{KTH}$ \\ School of Computer Science \\ and Communication, CSC \\ Valhallav. 79 \\ 10044 Stockholm \\ Sweden \\ ahedman@kth.se
}

\author{
Yngve Sundblad \\ Kungliga Tekniska Högskolan, \\ $\mathrm{KTH}$ \\ School of Computer Science \\ and Communication, CSC \\ Valhallav. 79 \\ 10044 Stockholm \\ Sweden \\ y@kth.se
}

\begin{abstract}
This paper is motivated by our work in the European Culture project "Faust - or dis-inventing the A-bomb". The project explored how to raise consciousness about distressing technology development through dialogue with old and young people. When reviewing our work it struck us that we had overlooked that some of the prototypes designed by the young participants called for embodied participation. We had naively expected to see sheer technology innovations of the future. Here we reflect on sensitivities for the bodily/physical will to interact.
\end{abstract}

We also discuss everyday life situations that could allow for natural physical engagement as a health benefit. Physical aspects are typically of little consideration in design projects, apart from projects that has bodymovement as specific focus. We seek ways to adequately include a critical perspective in future design and to consider physical aspects more broadly in ICT projects for a human sustainable future. In many cases, the young participants showed us their concern for sustainability and well-being of both the environment and themselves and demonstrated through their prototypes a willingness to contribute through physical interaction.

\section{Author Keywords}

Physical interaction design; interaction design for the body; physical power; movement; interactivity; participation; motivation; design and sustainability

\section{ACM Classification Keywords}

H.5.2

\section{INTRODUCTION}

ICT development has provided us with artefacts that are not only portable, but in some cases wearable. These technologies are embedded into a broad variety of fabrics. Smart technologies appear in home appliances, in transportation, in sports equipment, in business systems, in Permission to make digital or hard copies of all or part of this work for personal or classroom use is granted without fee provided that copies are not made or distributed for profit or commercial advantage and that copies bear this notice and the full citation on the first page. To copy otherwise, or republish, to post on servers or to redistribute to lists, requires prior specific permission and/or a fee.

OZCHI'12, November 26-30, 2012, Melbourne, Victoria, Australia. Copyright 2012 ACM 978-1-4503-1438-1/12/11 ...\$10.00. medical equipment, in learning equipment, in gaming systems and entertainment. The artefacts and systems can be used through interfaces such as touchscreens in various size and format, through soft, virtual or conventional keyboards and through various forms of pointing devices, through gesture, eye tracking, full body-movement among other interaction modalities.

In interaction research, focus has gone from Human Factors and Ergonomics to Human-Computer Interaction research with an early focus on information processing theories and cognitive models, to usability, to novel interaction design focusing on user experience and embodied embedded experience.

Here we explore an alternative perspective on physical interaction that we term physical movement participation. One of its key components is physical exercise as a component of interacting with technology. In discussing this perspective we will report from a study of a European project funded through the Culture Program. In this study, teenagers were asked to design future technologies. We found through reviewing our observations that the participants expressed a desire to include the body in their designs of technology. This may express a natural desire. It is a fact of nature that our bodies need to have some "workload" stressed on the system every day. We submit that there has been a focus on interaction for the mind ever since Douglas Engelbart wrote about man-machine interaction as a way of "augmenting the human intellect" but we can also think of technology as augmenting the body. Not in a fancy cybernetic way, but in a basic physical way that allows us to engage in healthy exercise while using technology.

\section{PHYSICAL INTERACTION IN ICT}

In design of interactive systems designers have sought to minimize physical effort. Information technology is usually lightweight and requires little work-light tapping on touch-screens, mouse movements or typing on physical keyboards. Most carried ICT equipment, such as cell phones, tablets and laptops can although light weighted feel heavy after a short period of time depending on the way they are carried or handled. However, while the stationary work place has been ergonomically explored and is well understood, the mobile work situation has received 
much less attention. The macro-monotony of movements in, for example earlier line production has become physically strained micro-monotony in front of portable equipment (Richter et al., 2009) and (Gustafsson et al., 2009). Since the use of mobile technology has grown in comparison to stationary equipment (Rupnik, 2009) and this trend continues we find reason to further investigate this area.

In line with a general view of technology as best being effortless to use, a common goal has been to make technology disappear or blend in with the rest of the world. Within Human Computer interaction (HCI) and Interaction Design (IxD) work has frequently been motivated by Weisers' notion of Ubiquitous Computing and the idea that information technology ought be weaved "into the fabrics of everyday life" (Weiser, 1991). In Europe, the European Commission's "Disappearing Computer" initiative was inspired by the metaphor of information technology becoming invisible and as such less physical demanding. One of the ideas was that "it is just there and responds to our desires anyway". Today we can find many examples of technology that has become ubiquitous (and almost nonphysical) in everyday-life. In our home environments, we have designed our appliances and electronics so as to be physically undemanding. For example, tapping on a glass surface regulates ceramic stoves while TVs can be controlled through gestures or voice. Driving a car or even a train requires about the same physical expenditure as playing a standard console video game. Such automation has been motivated from different perspectives, one being inclusion of users with different abilities. This, of course, has had a tremendous positive impact on many peoples quality of life. It is nevertheless partially a consequence of our automated western society that so many try to stay fit by attending different aerobics classes and gyms. We pay for physical exercise because we know that we need it and that it can also be enjoyable. We might say that our western culture has come to develop a gym concept of physical exercise. Exercise is something we often tend to do in commercial enterprises according to regimented schemes. Exercise is not something that we find throughout society the way it used to be in times past when physical labour was more common and our everyday appliances could not all be plugged into a wall-socket.

\section{PHYSICAL INTERACTION - A HIDDEN POWER?}

Although design work is typically presented as a tradition of combining hands and mind in the design process (Pekkola and Isomäki, 2011), we are concerned about the fact that typical ICT tools do not adequately accommodate and use the hidden power in our muscular system. In terms of electrical power consumption, the interactive systems may not be that demanding if we look at one item at a time but considering the many products, systems and artefacts that many of us use and interact with, the sum may come to a higher figure then we imagine. Whereas our physical, power expenditure may come to a much lower figure then we expect. Many of us sit for more than six hours a dayhours during which we reach a low metabolic rate close to baseline.
Designing modern interactive systems is typically a complex process, involving collaboration between people with a broad range of competences. The mix of competencies may span from knowledge of technologies (e.g., electronic and software engineering, multimedia, sensors, actuators, database, computer programming) to knowledge of people (e.g., anthropology, psychology, sociology, ergonomics and cultural studies) to knowledge of design (e.g., interaction design, product design, architecture, graphic design and to activities) and contexts (e.g., communities of practice, knowledge management and business) (Benyon, 2010).

Interaction designers are often in search of something new-some novel technology to make systems more interactive, intuitive, faster and more effective or amusing. With sustainability becoming increasingly important in modern society many are also looking for ways of designing low power, green information technology. The production of new high tech gadgetry, products and systems and their deployment requires large amounts of energy and material. This situation is becoming increasingly problematic. Reflecting on the above - future design solutions for many everyday activities could be designed to support physical activity that 'results in energy expenditure above resting level' (Cavall et al., 2006).

\section{Leisure work-time and hard work at leisure time}

Within the research community of Human Factors there is a growing discussion going on if we now may benefit from more physical demanding interaction (Straker and Mathiassen, 2009). The amount of time people spend sitting is said to augment the risk for many diseases (Warren, 2010). There are of course examples that do include physical force, one being systems as Nintendo Wii and Kinect, with a specific focus on physical activity. Reflecting on the above - future design solutions for part of everyday activities might produce physical activity that give 'results in energy expenditure above resting level' (Cavill et al., 2006).

The gym concept of exercise can be thought of analogously to John Dewey's museum concept of art (Dewey, 1934). Dewey was opposed to the way that aesthetic experiences had been relegated to separate institutions (museums) and disconnected from the rest of society. Instead he envisioned a society in which aesthetics was thought of as integrated with everyday life and work. He also in (Dewey, 1991) discusses the role of activity in thought training. We analogously envision a society in which physical exercise and the body are societally integrated as something to enjoy and derive benefit from not just in the gym. Such a design philosophy would take on a holistic picture of design for physical health.

\section{RELATED WORK}

We like to acknowledge that there are research already done with the aim of exploring and investigating the role of physical movement in HCI and IxD. Among others to mention are in no special order of appearances; Donovan and Brereton that developed a design game they called Meaning in Movements in order to explore what was going on in the dental practices (Donovan and Brereton, 2004). 
The notion of embodiment as described by Dourish in (Doursih, 2001). Holland et al., (Holland et al., 2009) looked into aspects of musical harmony and a prototype driven through whole body navigation. Hornecker and Buur in (Hornecker and Buur, 2006) explored social aspects of tangible interaction. Ishii presented his vision of bridging the gap between the digital and the physical environment in (Ishii, 1997). Larssen et al., (Larssen et al., 2005) arranged a workshop during the Critical Computing conference with the aim of exploring approaches to movement-based interaction. Loke et al (Loke et al., 2007) evaluated two computer games in order to extract knowledge from the relationship between body-movements and the output or the responses from used technology. Loke and Robertson (Loke and Robertson, 2009) extended the persona method to address movements in social interaction. Mueller et al (Mueller et al., 2009) explored to what extent the design of exertion games motivates people to actually use their effort to play. Rogers and Muller (Rogers and Muller, 2006) share their preliminary conceptual framework for sensor-based interaction. They found both benefits and downsides to "hands-free" controls. Finally we mention Rubidge and MacDonald (Rubidge and MacDonald, 2004) and their work on the Sensuous Geographies, an installation aiming at supporting and drawing attention to bodily attention.

\section{WHAT ARE WE LOOKING FOR?}

When analyzing research projects involved in designing prototypes and models of interactive systems a common approach is too look at the prototypes as context-free entities. It may be that when looking only at the results, e.g., the prototypes, or the working systems one may neglect to examine what users expressed through their interaction with the prototypes and during the design process.

Here we discuss our experiences of how youth can develop scenarios and prototypes for the future based on reflective practices (Schön, 1983) and how in our case, they lead to a reframing of interaction design - a reframing involving the body and physical exercise. Reflection has been characterized in (Fade, 2005) as involving describing, analyzing and evaluating thoughts, assumptions, theories and actions.

Our aspirations has been (1) to share our critical selfreflection when analysing interactive systems design research projects, and (2) to discuss the relationship between sustainability and forceful physical interaction in search of methods for sustainable future designs, both with regard to physical and environmental well being.

\section{THE FAUST PROJECT}

The theme of the Faust-project was to express and discuss questions and views regarding the 'social responsibility of the scientist', the social responsibility of oneself to others and each individual's responsibility for the future. Four partners in Italy, Sweden and UK were involved: an HCI research group, a free theatre group, a media institute and a film company. Part of the activities, a play, an interview with sir Joseph Rotblat, interviews with elderly and a panel discussion, were collected and used as reflection material in the work with the young people. In this paper we will focus on the participatory design activities in Sweden. For further information and details about the project visit http://cid.nada.kth.se/faust/.

\section{PARTICIPATORY DESIGN APPROACH}

The Human Computer Interaction research group at $\mathrm{KTH}$ in Stockholm has a long tradition of working with participatory design (Ehn, 1988, Bødker and Sundblad, 2008, Tobiasson, 2010). The methods used in the Faust project followed this tradition.

Participatory design has been used for information technology development in many settings such as museums, intergenerational communication, healthcare, schools, homecare, banking and media, as well as in government and NGOs (Sundblad, 2009). The approach has been effective both within and outside the research community. Participatory design has developed with no strict line between theory and practice and followed an interdisciplinary path to technology development. A typical participatory design scenario involves several stakeholders working together with designers and/or researchers in brainstorming and envisioning future design solutions as well as defining project goals (Blomberg, 2009).

This part of the project was performed in a multidisciplinary research team and can be seen as an example of complementing other research areas with a design approach to problem solving. As Lawson in (Lawson, 2005) states, design problems are often not apparent but have to be found. Dahlbom (Dahlbom, 2002) depicts design research not as concerned with 'truth', but with exploring possibilities for future living. On the other hand, it is also said that design research should not only be seen as knowledge support to existing design practice, design research "would instead be developed as a complement to other research areas that aims to contribute to the solution of major and minor problems in the community" (Ullmark, 2010). We consider young people's images of the present to influence future aspirations and will to participate in society to be of great value in design as also stated in (Hicks, 1996).

\section{WORKSHOPS IN SWEDEN}

From the HCI research group in Stockholm Sweden the activities with youth focused on workshops where they imagined themselves being researchers, addressing what are, according to them, current, major problems in the world. As researchers, we facilitated the activity and had developed the design briefs, but it was the participants' concerns and visions that guided the design process. We begun with letting them take part of collected project material, then the design briefs to kindle interest and trigger reflective action. After that a flood of events and processes naturally followed-brainstorming, discussions, lo-fi prototyping, scenario construction including videoprototyping and the preparing of an exhibition with posters and artful design. As described, in (Mackay et al., 2000) we used video-prototyping as one of the methods to make the prototypes come alive. In the acting out of scenarios of use, gaps in the design had yet another possibility to reveal 
themselves. The process of the Design is described in Figure 1.

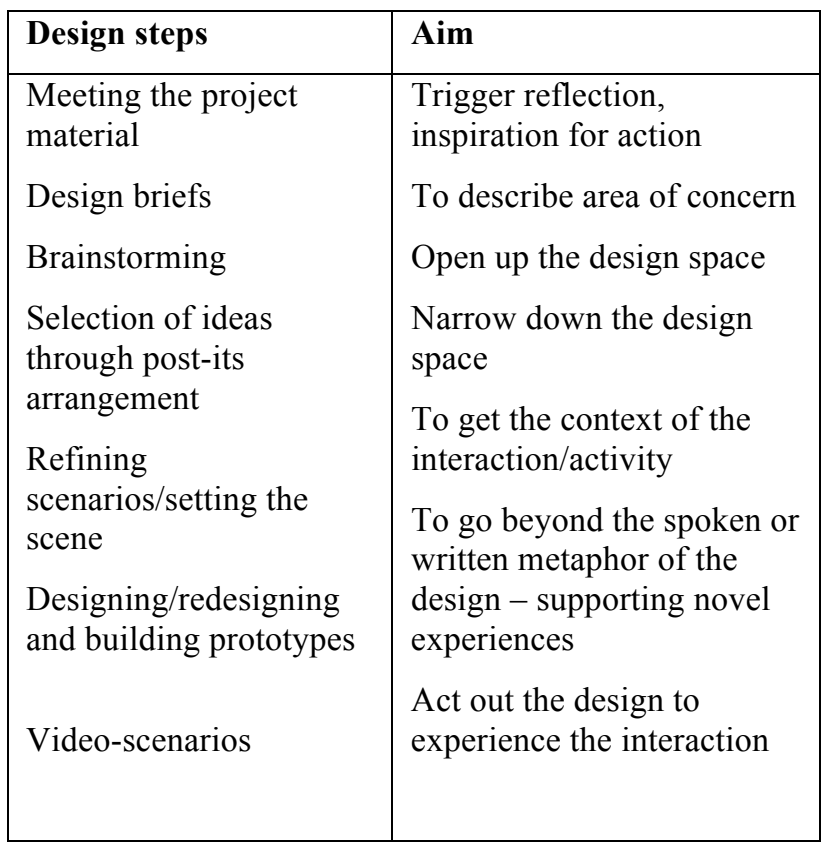

Figure 1. Process of the Design

The Stockholm workshops involved young students from an inner city school and two suburb schools. 33 students, between the ages of 13 and 18, participated in five full-day design workshops. We divided them into smaller groups and for reasons of social comfort and trust grouped peers together.

They generated a large amount of ideas, discussed these between themselves and decided on which ideas to develop further. After some initial research, they built low-tech prototypes and filmed video scenarios - how the products or services would work and how they could be used. In Figure 2 ideas and prototype work are being discussed with one of the researchers.

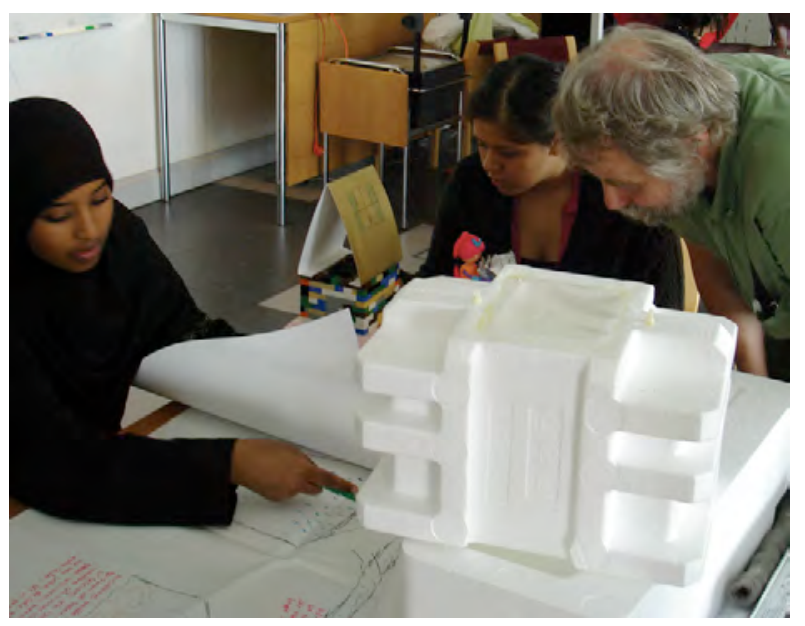

Figure 2. Prototype work with young students in Stockholm

\section{The prototypes}

During the workshops in Stockholm the following six prototypes were designed, produced, discussed, reflected upon and finally exhibited at the final event at the Nobel Museum.

\section{The Global Transporter}

This group produced a most environmentally friendly way of sharing the resources of our world-a globally connected pipe system, through which anything can be sent, anywhere at any given time. For example, Greenlanders can share ice as fresh water with Africans and local surplus of crops and other foods can be distributed anywhere. See Figure 3 for "work in progress". The group reflected on human imbalances in perceptive ways. Their discussions also concerned current transport possibilities and the need for environmental friendly and fair ways of distribution. They wanted a solution that would put an end to some of the areas of conflict. The system was in its center a computer system that could figure out and calculate ways to get the resources in balance. They discussed security and the network being problem areas for the design of the system. This group also discussed the problem that young people do not get as early access to information as they want. They discussed the problem with long distance transportations of food that motivates producers to choose genetically modified crops.

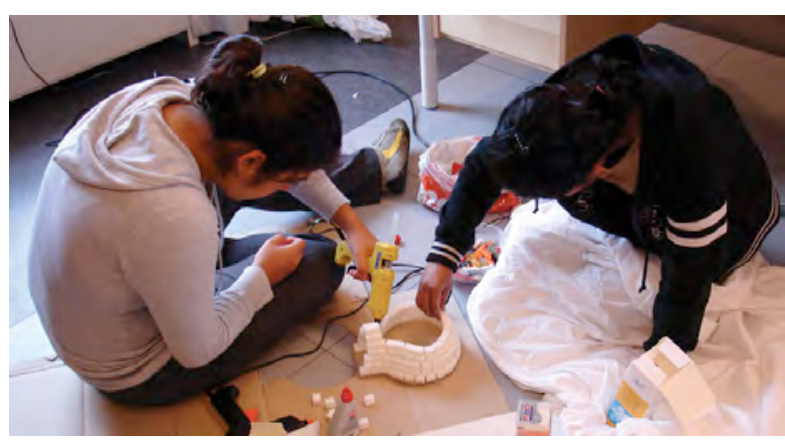

Figure 3. Prototyping The Global Transporter

\section{The Team Energy}

This group focused on waste of energy and developed an approach for making use of energy produced in everyday activities such as working out or walking. The group was also interested in concealing digital artifacts and developed design prototypes with technology hidden in wall decorations and pots of plants. They discussed that lack of information and shortage of motivation and engagement was problematic and that there was room for small simple solutions that could make a difference. They discussed that energy from physical heat and movement were not addressed or used. It was a waste of energy. Since that kind of energy would always be at hand as long as there were human beings on earth. They designed prototype models of their system. In Figure 4 the Team Energy are discussing their systems with museum visitors. 


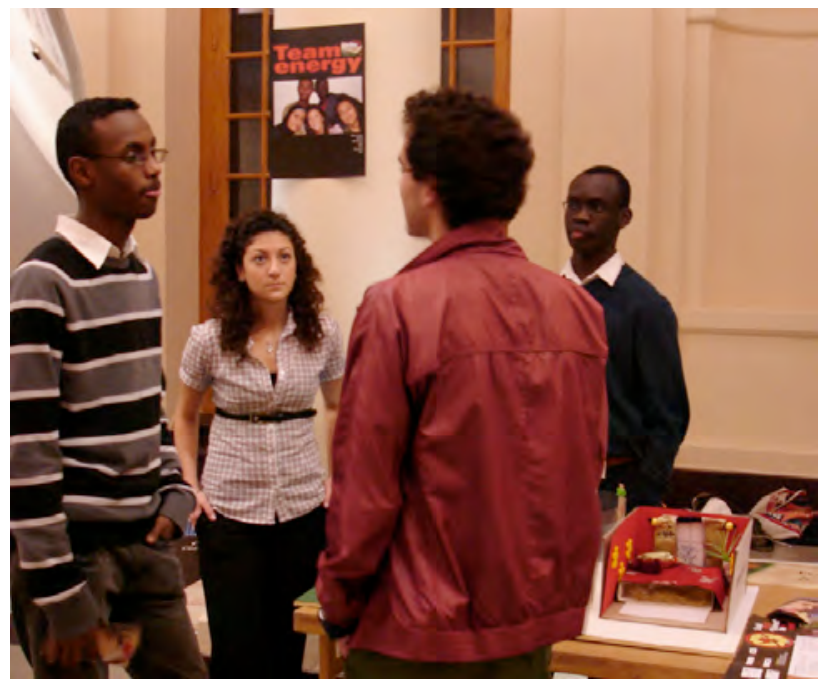

Figure 4. Discussing Team Energy

\section{The Separator}

The group highlighted the issue that we don't have enough fresh water in the world, which is cause for conflict and diseases. They discussed that although the world had come far in terms of science and technology we were behind when it comes to providing citizens of the earth with clean water. They also noted that the problem would increase with the global population explosion. They envisioned a technology for cleaning water, together with an energyefficient way of removing salt from salt water. On their poster they promoted it as "The machine that keeps people alive". In Figure 5 the design is tested and iterated.

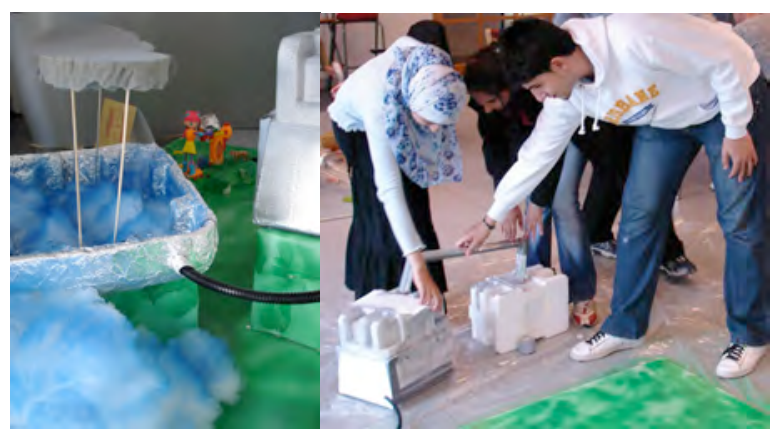

Figure 5. Designing the Separator

\section{The Hands free Jojo}

The group contemplated the rapidly increasing amount of electromagnetic radiation in our everyday environment, an issue we as of yet know little about in terms of possible negative consequences.

They discussed that scientist had not yet agreed upon if it was dangerous or not. They decided to "do something" at least it would be better to react and prevent a possible danger then to not do anything. They noted that current hands-free designs are difficult to use. The group came up with an idea for an easy to use hands-free cell phone that would expose the user to minimal amounts of radiation. Figure 6 shows it in use.

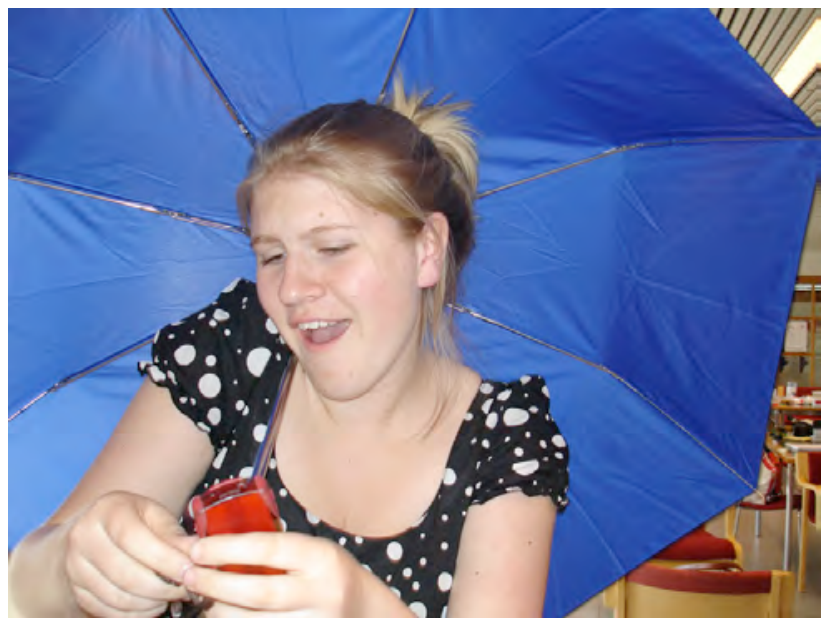

Figure 6. Video-prototyping the jojo

\section{FAVAHAMA}

This group discussed commuting and transportation with respect to energy consumption, waiting-times and land appropriation (e.g. in order to build highways) in urban environments. The group made a large-scale hovercraft public transport system without need for tracks or roads. Their design contains several innovative ideas. Figure 7 shows the Hover-vehicle. The energy needed is produced by the passengers themselves, as exercise bikes are hooked to generators. If you're in the mood for a work-out, the fee for the trip is reduced according to the amount of your efforts.



Figure 7. One part of the FAVAHAMA-system

\section{The Carry-On Photo Synthesis}

This group discussed and showed concern for the amount of trash and garbage that in the handling process available today produce toxic bi-products. They designed a system that would, through a long serious of activities, turn this procedure into something that could be of use for saving energy and cleaning the air that got polluted by the burning process. They made one system portable for individual use. The group explored how to make use of exhaled carbon dioxide to keep plants alive. They reflected on plants as producing both a nice atmosphere and pleasant scent. In Figure 8 they demonstrate the system for visitors at the Nobel Museum. 


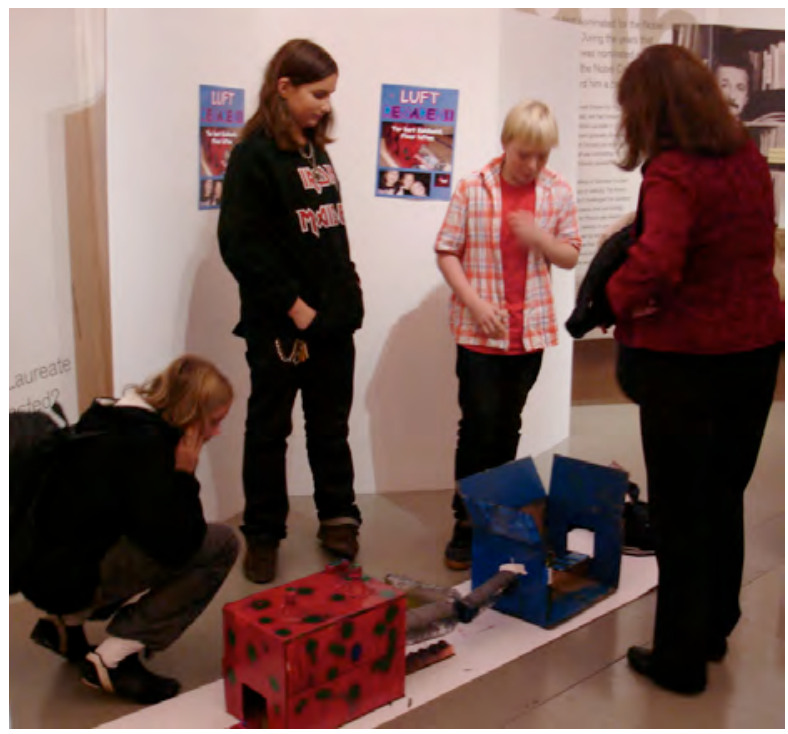

Figure 8. Demonstrating the Carry-On Photo Synthesis

\section{Final event at the Nobel Museum in Stockholm, SWE}

During a final event at the Stockholm Nobel museum the $20^{\text {th }}$ of October 2006, the work by the young students was disseminated, together with the Faust project as a whole. The event was divided into an internal two-hour presentation and a public exhibition. Active participants were the 33 young students and 3 of their teachers from Kista and Vällingby in Stockholm. From Birmingham and London there were 6 students and 2 teachers. The project members from Stockholm, London and Rome were 7 in total. Finally there were invited guests and visitors at the Nobel Museum.

First presentations were given with short videos and pictures with the old interviewees, with Joseph Rotblat, the Faust in Hiroshima play, the London panel, the young students dance performances from Italy and the UK young students theatre performance. A lively discussion on the experiences followed, where, as seen in Figure 9, everyone were very active. The second part of the final event was the public exhibition for the general audience, with stations demonstrating the UK youth theatre activities, the Italian youth dance performance and with the prototypes from the six projects with young students in Stockholm.

The young people were present along with their design prototypes and they explained their work and discussed with the visitors. Also here they showed strong involvement and pride of their inventions, manifested in the prototypes. Figures 4 and 8 show visitors in dialogue with the young project members, who produced quite informative and ingenious exhibits at the Nobel museum.

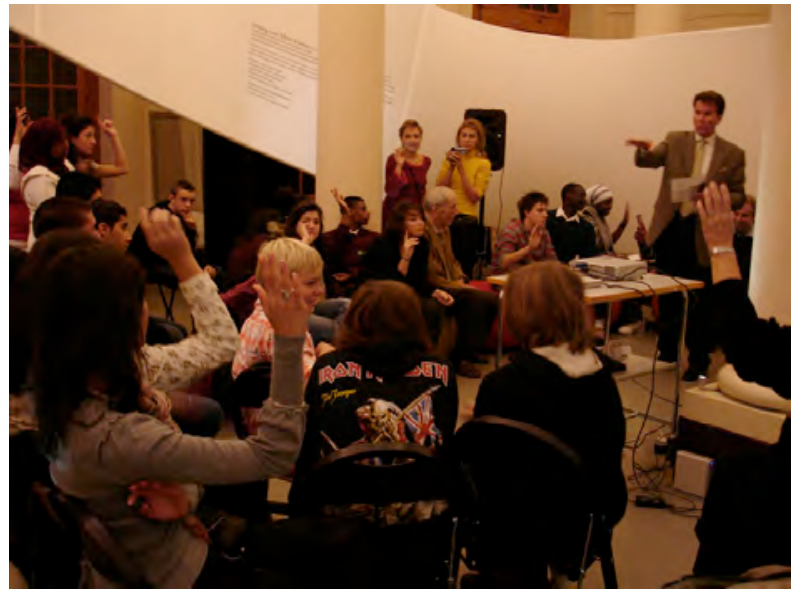

Figure 9. Discussion during the Nobel Museum event

\section{ANALYSING THE MATERIAL}

When we analysed the material of photos, videos, notes, posters and prototypes some interesting aspects become salient. The way the young students worked and the way they communicated that the innovations and the prototypes were supposed to function was something we almost had initially neglected. The interaction designs included users as physically engaged and often as sources of alternative power - a hidden power. A physical power considered in action. The young students design proposals and solutions did not merely focus on technology inventions, although they showed both great interest in and understanding of technology. Their designs suggested, from the perspective of sustainability, how to take active part in local transportation (in a combo bus/bicycle), and how to make use of energy that we produce in our everyday activities (such as going to the gym).

That can be put in contrast to recent years' design of interaction technology and interfaces that demand nothing or very little of our physical capacity e.g. a slight touch with our index-finger or some blinking with our eyes in order to respond.

In the Faust-project, young people were involved as participants for the development of future scenarios. The design "problems" were not outlined beforehand. The project's outcomes are ranging from conventional ideas about the future, adaptability and resilience towards current solutions and also anxiety and pessimism about the young participant's own future prospects.

The Global Transporter - A quite utopian design in hope for a computer system to solve the man-designed problems. They showed concern for not being included and not receiving information around future design and problem-solving. Connection and sharing not only information but likewise goods.

The Team Energy - A small scale practical solution for alternative power use. They designed for the technology to be hidden in more aesthetically compelling objects such as plants. There are similar ideas and solutions but the physical engagement and willingness these students expressed in their design we think is something to consider. They put forward that they perceive themselves 
as being able to produce energy in a sustainable way and hope for this to be used and not wasted. As when working out in a gym produced they discuss that as actually using and possibly producing energy if saved.

The Separator - the imbalance of resources put in hightech solutions were areas for conflict according to this group is also around basic need such as the one for fresh water. Still they demonstrated belief in technology and machines with the solution of "The machine that keeps people alive".

The Hands free Jojo - This was one of the prototypes that we initially somewhat neglected. It was not something world-saving. But they showed concern about something in their everyday life. Now this solution may be a little outof date since the use of headphones in combination with music and phone is almost constantly in every-ones ears. In their demonstration video it came clear that the phone seem quite central in young girls lives for communicating.

FAVAHAMA - this design solution show a combination of human and technology power-energy use. Their video (although in Swedish) will be attached as an example of the enthusiasm the young students show of being able to combine and participate. From our side it took time to see all the perspectives this design solution promoted. Why not get your opportunity for gym activities during everyday activities such as transportation? They showed through their design a perspective on themselves and their bodies as something worth considering when designing for engagement and sustainability. In this example they use local transportation.

The Carry-On Photo Synthesis - when everything else is becoming personalized and portable why not your own carry-on photo synthesis? The member of this group was among the youngest in the workshops. In this presentation as in the Hands free Jojo, the Carry-On Photo Synthesis is something designed to be carried on a personal level. They did reflect on issues of human movement and circulation. We produce material in our breathing process that can be used for a beneficial relation between humans and nature. This design augmented that relation. It demonstrate a clear example of the close relation between human and nature something that may not be that obvious in city.

\section{DISCUSSION}

Participation provides young people with opportunity to reflect and have an impact on their future. Worth special mention from the Faust project is the idea of making use of energy produced by the activities of the users. As mentioned earlier, one group developed a concept for how to make use of energy produced in everyday activities such as working out in a gym or walking. Another group presented an idea of a transportation system that uses energy produced by the passengers themselves.

Initially we did not "see" these parts of the prototypes as expressing an underlying concern. We did not "see" it as a will to contribute and to show concern for the world and the future. In the analysis this became clear that it illustrates these young students considerations of participating with the whole body in design solutions and their concern for energy consumption. The design space of the young students encompasses consideration of all human capacities, not only design for information and communication skills that tend to be limited to the mind. Our experiences are that the physical perspective can and should be used as a valuable resource for critical reflections on the present and future solutions. This we believe is useful both for different end-users and for us as design researchers to reframe our thinking.

The young participants noticed many problematic issues about present solutions that they wanted to address. Whereas many design projects develop technologies that assist us in various ways, our concern is the user situation merged with the context of healthy living. For example, how could interaction design help with the lack of physical activities? Information technology has traditionally contributed to depriving us of physical work. In some ways the words information age is indicative of how the body has been neglected-'the nothing-but-thinking age', a reduction of the human body to the mind. But it should be possible to reverse this trend and in the hands of interaction designers lies possibilities to contribute to our future well-being. Health-workers such as occupational therapists and physical ergonomists are typically consulted late in response to problems and seldom for preventive measures. We propose to expand the notion of participation in design to include a broader focus on physical abilities. This, we believe, would benefit a more sustainable human development both in the present and in the future.

Physical aspects and embodiment has gained a greater interest in the HCI and IxD research community. The motivation is among other things to explore new interaction modalities. Work has been done within dance, sports, leisure activities such as horse riding, skating and skiing. Apart from projects that have body-movement as specific focus the physical force, seems rather marginalized. Revisiting our work we saw that the young students had considered this. In many cases, they showed concern for sustainability and well-being of both the environment and themselves and demonstrated, through their prototypes, a willingness to contribute through physical forceful and powerful interaction.

Participatory design has been used in various settings from the 70ties. Augmenting the voice of the user, developing work-tools, systems and organizations including a usercentric perspective has been part of the driving perspective. The knowledge of the user has been worth considering following the arguments that they who shall use the software have the knowledge of how these should be designed.

If using the same arguments towards our physical skills, one could reflect on the value of augmenting "the voice" of the body - when and how do we "ask" the body how it would like to be used, how it would like to interact? The physical ability has a broad variety of possible actions, among others, to grasp, tear, drag and drop, to manipulate, lift, carry, work-out and relax. We sometimes come running with solutions of pain and sour muscle from sitting 
hour on ends in the same position may it be in the office or at home or at a café.

In the same line the balance in the interaction between computer technology and human physical ability and power, the actual movements performed in most computer interaction does only involve a minor part of our physical ability and force. Although computers used to be roomsized and now are in palm-size we as people has not grown room-sized but research are pointing towards the amount of hours we are sitting as part of the reason for our augmenting in size and receiving pain and sour muscle from sitting hour on ends in the same position may it be in the office or at home or at a café.

How can we as researcher be more skilled in perceiving bodily expressed wishes, needs and knowledge? A future research question we regard as worth exploring is how physically sensitive design thinking could be implemented in the design process. We hope to further explore and discuss physical Innovation, Immersion, Integration, Inclusion and Interaction for play and life.

\section{CONCLUSION}

We have discussed design research with the aim of illustrating how easy it seem to forget to include the physical perspective when almost everything can be designed for automation and computer power. We return to Dewey's words, reflection is to turn something over in the mind and give it serious consideration. Our aspiration is that our readers will give physical aspects in design serious consideration. We argue for body-movement as a forceful intelligent sustainable power in the design of human technology interaction.

We find good reasons to include an eye on the way people move and like to physically participate when engaging in interaction design. Technology seldom needs more of our physical abilities then a spot may it be small as in our fingertips or big as when tracking our movements but technology also needs power. There can be a way to balance the energy consumption between computer technology and humans. As there is a joy in the feeling of being able to contribute - to give something. Might it even be energy through physical activities.

When evaluating and reflecting on any kind of system within these domains it could be of great value to be sensitive to the aspect of physical participation and how it may yield benefits in terms of well-being, preventive health measures and perhaps also sustainability.

Incorporating physical design-for-the-body or as we put it physical movement participation in interaction design could provide for healthy critical dialogue among stakeholders.

The youth of the Faust project explored a wide range of topics and ideas. Together they showed enthusiasm and sincere concern for the future. Many of their design work depended on elements of physicality and involvement of the human body in ways that supported sustainability.

From the final event we conclude that the methods and activities used in Faust, especially workshops, produced strong involvement and inventiveness, passion and understanding of humanist values, among the participants from Sweden, Italy and the UK.

From a perspective of current and future wellbeing it may be of great concern to include methods to invite physical power to contribute and interact. What you see is what you get, what you think is what you design, so we propose including these perspectives. There is a, somewhat, hidden "power" that can come into play.

\section{ACKNOWLEDGMENTS}

This research was funded through the Culture Programme of the European Commission. We would like to thank all participants in this joint adventure. The young and the old people, the schoolteachers, the people at the Nobel Museum, the visitors and finally our professor Yngve Sundblad for participating and granting us the possibility to explore.

\section{REFERENCES}

Benyon, D. (2010): Designing Interactive Systems: A Comprehensive Guide to HCI and Interaction Design 2nd ed. USA: Pearson Education, 2010

Blomberg, J. (2009): On Participation and Service Innovation. In T. Binder, J. Löwgren, \& L. Malmborg's (Eds) (Re)Searching the digital Bauhaus. pp. 121-144. London: Springer Verlag

Bødker, S. \& Sundblad, Y. (2008): Usability and interaction design - new challenges for the Scandinavian tradition, BIT (Behaviour \& Information Technology), vol.27, no.4, pp 293-300.

Cavill, N., Kahlmeier S. and Racioppi F. (Eds) (2006): Physical activity and health in Europe: evidence for action. Copenhagen: Copenhagen World Health Organization, Regional Office for Europe

Dahlbom, B. (2002) "The Idea of an Artificial Science". In Dahlbom, Beckman \& Nilssons (Eds) Artifacts and Artificial Science. pp. 9-42. Stockholm: Almquist \& Wiksell

Dewey, J. (1910/1991): How we think. Buffalo, N.Y.: Prometheus Books

Dewey, J. (1934) Art as experience, N.Y.: Minton, Balch \& Company.

Donovan, J. and Brereton, M. (2004) Meaning in Movement. Proceedings of the Participatory Design Conference, PDC2004, pp163-166,

Dourish, P. (2001) Where the Action is: The Foundations of Embodied Interaction, MIT Press

Ehn, P. (1988) Work-oriented Design of Computer Artifacts. Stockholm: Arbetslivscentrum

Fade, S. (2005): Learning and Assessing through Reflection: a practical guide. Available at http://www.practicebasedlearning.org/resources/material s/docs/RoyalBromptonV3.pdf (assessed 2012-01-14)

Gustafsson E., Johnson P.W. Hagberg M. (2009). Thumb postures and physical loads during mobile phone use - A comparison of young adults with and without 
musculoskeletal symptoms. J Electromyography and Kinesiology

Hicks, D. (1996): A Lesson for the Future- Young people's hope and fears for tomorrow. Futures, Vol. 28, No. 1, (1996), pp. 1-13

Holland, S., Marshall, P., Bird, J., Dalton, N., Morris, R., Pantidi, N. Rogers, Y. and Clark, A. (2009) Running up Blueberry Hill: prototyping whole body interaction in harmony space. Proceedings of Tangible and Embedded Interaction, ACM, 93-98.

Hornecker, E. and Buur, J. (2006) Getting a grip on tangible interaction: a framework on physical space and social interaction, CHI '06: Proc. SIGCHI conference on Human Factors in computing systems. ACM

Ishii, H. (1997) Tangible Bits: Towards Seamless Interfaces between People, Bits and Atoms, CHI '07 Proc. SIGCHI conference on Human Factors in computing systems. ACM.

Larssen, A., Robertson, T., Brereton, M., Loke, L. \& Edwards, J. (2005) Eds: Workshop Proceedings: Approaches to Movement-Based Interaction held in conjunction with Critical Computing 2005 Between Sense and Sensibility, The Fourth Decennial Aarhus Conference, Aarhus, Denmark, August 22-24 ISBN 09757948-0-9

Lawson, B. (2005): How designers think: the design process demystified. Oxford: Architectural Press, Elsevier

Loke, L. and Robertson, T. (2009) Design representations of moving bodies in interactive, immersive spaces. International Journal of Human-Computer Studies. 67, 4: pp. 394-410.

Loke, L., Larssen, A. T., Robertson, T. and Edwards, J. (2007) Understanding Movement for Interaction Design: Frameworks and Approaches, Personal and Ubiquitous Computing, Special Issue on Movement-Based Interaction. Springer, 11, 8: pp. 691-700.

Mackay, W.E., Anne V. Ratzer, A.V. and Janecek, P. (2000): Video artifacts for design: bridging the Gap between abstraction and detail. In Proceedings of the 3rd conference on Designing interactive systems (DIS '00)

Mueller, F., Agamanolis, S, Vetere, F., Gibbs, M. R. (2009) A Framework for Exertion Interactions over a Distance, SIGGRAPH 2009: 36th International Conference on Computer Graphics and Interactive Techniques, New Orleans (3-7 Aug)

Pekkola, S. \& Isomäki, H. (2011). (Eds.) Reframing Humans in Information Systems Development Computer Supported Cooperative Work, 2011, Volume 201, Part 3, 227-242, DOI: 10.1007/978-1-84996-347-3 14
Perry, M. \& Brodie, J. (2006). Virtually connected, practically mobile. In Andriessen, J.H.E.(Ed.) Mobile virtual work: A new paradigm? Springer, Berlin

Richter, J. M.; Mathiassen, S. E.; Slijper, H. P.; Over, E. A.; Frens, M. A. (2009). Differences in muscle load between computer and non-computer work among office workers in Ergonomics 2009 (52) pp 1540-55

Rogers, Y and Muller, H. (2006) A framework for designing sensor-based interactions to promote exploration and reflection. International Journal of Human Computer Studies, 64 (1), 1-15.

Rubidge, S. and MacDonald, A. (2004) Sensuous Geographies: a multi-user interactive responsive installation. Dig Creativity 15(4) 245-252Anderson, R.E. Social impacts of computing: Codes of professional ethics. Social Science Computing Review 10, 2 (1992), 453-469.

Rupnik, R. (2009): Handbook of research in mobile business: technical, methodological, and social perspectives. Information Science Reference, Hershey

Schön, D. (1983): The Reflective Practitioner: How professionals think in action. London: Temple Smith, 1983.

Stolterman, E. (2003). "IT Artifacts in Design Work: How Technology Reveals Practice" in Järvi, T. \& Reijonen, P. (eds) "People and Computers: Twenty-one Ways of Looking at Information Systems"

Straker, L.; Mathiassen, S. E. (2009). Increased physical work loads in modern work--a necessity for better health and performance? In Ergonomics 2009 (52).

Sundblad, Y. (2009): From Utopia 1981 to Utopia 2008, in Binder, T., Löwgren, J. \& Malmborg, L. (eds.) (Re)searching the Digital Bauhaus, Springer, October 2009, pp.13-41.

Tobiasson, H. (2010): There's more to movement than meets the eye - Perspectives on physical interaction. Licentiate thesis. Stockholm: Royal institute of Technology

Ullmark, P. (2010): En ny roll för designforskningen. Available at http://designfakulteten.kth.se/forum/artiklar/en-ny-rolldesignforskningen

Warren TY, Barry V, Hooker SP, Sui X, Church TS, Blair SN. Sedentary behaviors increase risk of cardiovascular disease mortality in men. Med Sci Sports Exerc. 2010;42(5)

Weiser, M. (1991): The Computer for the 21st Century, Scientific American, Sept.1991 